\title{
Potential for the environmental impact of transgenic crops
}

\author{
Philip J. Dale ${ }^{1 *}$, Belinda Clarke², and Eliana M.G. Fontes ${ }^{3}$
}

\begin{abstract}
In recent years, there has been increasing interest in how changes in agricultural practice associated with the introduction of particular genetically modified (GM) crops might indirectly impact the environment. There is also interest in any effects that might be associated with recombinant and novel combinations of DNA passing into the environment, and the possibility that they may be taken up by microorganisms or other live biological material. From the current state of knowledge, the impact of free DNA of transgenic origin is likely to be negligible compared with the large amount of total free DNA. We can find no compelling scientific arguments to demonstrate that GM crops are innately different from non-GM crops. The kinds of potential impacts of GM crops fall into classes familiar from the cultivation of non-GM crops (e.g., invasiveness, weediness, toxicity, or biodiversity). It is likely, however, that the novelty of some of the products of GM crop improvement will present new challenges and perhaps opportunities to manage particular crops in creative ways.
\end{abstract}

Debates about the commercial introduction of GM crops in some parts of the world have led to questions about their potential impact on the environment. Could they affect non-target insects, outcross to produce uncontrollable weeds, or have adverse effects on wildlife? To what extent could they benefit the environment by reducing certain chemical inputs into agriculture or providing raw materials currently obtained from non-renewable sources? Although it is acknowledged that agriculture inevitably has an impact on the environment, what is a reasonable trade- off between crop production, wild life, and consumer concerns?

Theassessment of the environmental impact of GM crops is a fundamental part of the international regulatory process undertaken before GM crops can be grown under field conditions experimentally or commercially. As a consequence, it has been the subject of research over the past 15 years ${ }^{1}$. In 2001, 52.6 million hectares (130 million acres) of GM crops were grown commercially, and there has been extensive experience of GM crops in commercial agriculture in over ten countries?

The objective of this review is to outline what is known about the different kinds of environmental effects of GM crops and to discuss the principles and questions that have emerged from the assessment of environmental impact so far. To consider the present state of knowledge is timely, not least because Europe is in intense discussions about whether to commercialize GM crops, some of which have been in the regulatory pipeline for several years. The literature on the topic is extensive, so we will illustrate the nature of potential environmental impacts with examples. We also aim to identify gaps in knowledge and provide signposts to areas where further research is needed.

One of the most challenging issues in assessing environmental effects is in deciding what constitutes an acceptable or unacceptable environmental impact. Discussions of this type tend to step outside the real ms of science into value judgments about the relative importance of different living things. A question often asked is: should the environmental impacts of GM crops be compared with those from conventional, organic, or integrated farm management practices? This is a fascinating and important area of debate, but it is outside the scope of this review. For our purpose here, environmental impacts will be compared against a baseline of non-GM conventional agricultural practice that is the predominant form of agriculture internationally.

We concentrate on the scientific analysis of environmental impact and do not discuss socioeconomic or ethical issues. The primary questions about environmental impact arethe same regardless of the method of plant breeding used: what is the nature of the genetic change, how is the genotype and phenotype of the crop modified, and what is the environmental consequence of that change? Wehave divided the topic to consider two issues: direct effects of the crop on the environment, and indirect effects on the environment by changing agricultural practice (Fig. 1). The fate and impact of naked DNA in the environment is also considered (see "Fate of free DNA in the environment").

\section{Toxicity to living things}

Non-target effects are defined as undesirable effects of a novel gene (usually conferring pest or disease resistance) on "friendly" organisms in the environment. Identifying a resistance gene and targeting its product to appropriate plant tissues so that it acts only against the pest, without adverse effects on friendly organisms, is challenging. This is particularly true where the benign or beneficial organism is related to the pest to be controlled and shares similarities in physiology. Targeting the pest without undesirable side effects is a potential problem for all methods of control, whether chemical or biological.

The use of toxins by plants for defense against pests and diseases is a common phenomenon in nature. Somenatural defensesubstances can be highly toxic, such as glycoalkaloids in deadly nightshade (Atropa belladonna) and ricin, found in the caster bean (Ricinus communis). Transgenic pest-protection strategies generally depend on

${ }^{1}$ John Innes Centre, Colney Lane, Norwich NR4 7UH, UK. ${ }^{2}$ Norwich Research Park Science, PO Box 715, Norwich N R4 7SY, UK. ${ }^{3}$ Embrapa-Cenargen, PqEB-Final Av. W3 N orte, Brasilia, DF70770-900, Brazil. *Corresponding author (phil.dale@bbsrc.ac.uk). 
Table 1. Potential impacts* of GM crops on the environment

Class Example

\section{Direct impact of novel traits on the environment}

Chemical interaction with living things Non-target effects of insect resistance

Fate and consequence of insecticidal toxins in soil

Change in persistence or invasiveness of the crop

Persistence in agricultural habitat (weediness) Invasiveness in natural habitats

Gene flow by pollination to weeds and feral plants

Transfer of herbicide tolerance to weeds

Transfer of biotic and abiotic stress tolerance to weeds or feral species

Stacking of herbicide tolerance genes

Indirect impact of changing agricultural practice on the environment

Reduced efficiency of pest, disease, and weed control

Effect on wildlife biodiversity

Effect on soil and water

Development of weeds tolerant to herbicides by evolution and selection from within the weed genepool

Development of resistance to $B t$ toxins in pests

Effects of broad-spectrum herbicides

Change in herbicide use

Change in soil cultivation patterns

*Impacts can be detrimental or beneficial. Risk assessment focuses primarily on the analysis of potential negative effects on the environment.

the transfer and expression of novel or natural defensive plant genes ${ }^{3}$. The most extensively studied examples of engineered resistance are based on the use of delta endotoxins of the bacterium Bacillus thuringiensis (Bt). Bt is a naturally occurring ubiquitous soil bacterium that produces a toxin lethal to certain insects.

One of the most significant studies of non-target impacts has been on the effects of $B t$ insecticidal proteins on the monarch butterfly in the United States. A laboratory study published in 1999 suggested that "Bt maize" was a potential hazard to monarch butterfly larvae consuming milkweed leaves (Asclepias spp.) with pollen from corn containing a Bt gene sprinkled on the milkweed leaf surface 4 . This initial study did not assess the ecological consequences of these findings. It measured thetoxicological response of monarch larvaeto the toxin, but did not investigate the level of exposure of the insect to the toxin in natural field conditions. This report generated worldwide interest and, in consequence, a collaborative research program was established in 1999 (ref. 5). The research focused on acute and toxic effects of Bt corn pollen and the degree to which monarch larvae would be exposed to toxic amounts of Bt pollen by feeding on milkweed plants found in and around cornfields. The authors of this study reported that, although Bt pollen does have some toxic effects on butterfly larvae, the pollen densities likely to be encountered are low and pose negligible risk to the monarch.

It has been observed, however, that the toxic properties of the Bt maize pollen differ among Bt maize lines. Thetransformation events with the highest expression of Bt have the greatest adverse effect on the monarch ${ }^{6}$. It is likely that in the future, greater attention will be given to gene promoters of $B t$ and transformation events that lead to negligible or no Bt expression in pollen. An ideal pest resistance mechanism is sharply targeted so that it inhibits the pest of interest and has limited non-target effects on other herbivores and organisms in the environment. Assessments may need to be made of the possibility that the ecological niche vacated by a primary crop pest could be filled by a secondary herbivorous pest.

Other laboratory and field studies have looked at theeffects of GM Bt crops on pest predators or parasites. In most cases, these studies measured the development and survivorship of insect predators reared on herbivore prey that had ingested corn leaves expressing Bt toxins. Research by Hilbeck et al. 7,8 reported the following: first, lacewings reared on Ostrinia nubilalis (European corn borer, ECB) or Spodoptera littoralis that had ingested corn leaves expressing Bt CrylAb toxin showed increased mortality and delayed development; and second, high concentrations of CrylAb in an artificial diet fed directly to lacewing larvae were toxic. These laboratory studies also emphasize the difficulties of conducting ecologically relevant laboratory experiments. The dose of toxin used in the final experiment was 30 -fold higher than that found in most corn tissues in the field. Moreover, exposure in the field is not continuous as the predator has a choice of other insects or eggs to feed on. In the case of the ECB/lacewing study, the larvae in the field died soon after eating Bt corn plants. Any surviving larvae would normally feed inside the corn plant for most of their lives and would therefore not be available for consumption by lacewings 9 .

Caution must be used when drawing conclusions from results of small sets of laboratory studies that test non-target species under unnatural conditions or focus on hazard alone, without considering the level of exposure that occurs under natural conditions. The type of effect on natural enemies of plants depends as much on the specific attributes of the resistance mechanism as it does on the details of the interactions among the target and non-target species- that is, their host/prey interaction, and the plants on which this interaction occurs ${ }^{10}$.

The issue of baseline environmental impact is particularly relevant here because there is good evidence that the pesticidal sprays used on maize may be moreharmful to the monarch butterfly than is Bt corn pollen ${ }^{11}$. In evaluating the use of Bt crops and their possible environmental damage, it is important to take into account the environmental damage caused by the use of pesticides in agriculture generally. It is argued that millions of birds and billions of insects, both harmful and beneficial (including pollinators and biological control agents), are killed each year in the United States alone as a result of pesticide use.

Widespread use of chemical pesticides to control primary pests often disrupts the natural controls that prevent the outbreak of secondary pests by destroying natural insect enemies. If the planting of GM pest-resistant crop varieties eliminates the need for broad-spectrum insecticidal control of primary pests, naturally occurring control agents are more likely to suppress secondary pest populations, maintaining a diversity and abundance of prey for birds, rodents, and amphibians.

It has also been proposed that the incorporation of resistance to potato leaf roll virus may preclude the need to spray against the aphid vector of the virus ${ }^{3}$. It is expected that as a consequence of allowing the number of aphids to increase, the number of natural control beetles (ladybirds) would also increase. This kind of application of disease resistance may have a direct benefit in increasing the numbers of natural pest predatorsin agro-ecosystems.

The fate and consequences of insecticidal toxins in soil is also an important consideration. It has been shown that Bt plants exude Bt toxins from their roots during their entirelife cycle, and that the toxins are also released from dead plant material incorporated into the soil after harvest ${ }^{12}$. Bacillus thuringiensis is a ubiquitous soil-borne 
bacterium that naturally releases Bt toxins into soil. But Bt toxins from crop sources are likely to result in the additional exposure of soil organisms to these toxins. Saxena and Stotzky ${ }^{13}$ investigated the effect on soil organisms of CrylAb toxin released from roots and from crop residues. They found that the toxin was present in the guts and casts of tested earthworms. But there were no significant differences in mortality or weight of these organisms or in the total number of other soil organisms (including nematodes, protozoa, bacteria, and fungi) between the soil rhizosphere of Bt and non-Bt crops.

The Bt toxin can bind to elements within the soil (such as clay particles or humic acids), become stabilized ${ }^{14}$, and remain active for possibly hundreds of days 9 . As the toxin needs to be ingested to be active against insects, it is likely that toxins bound to soil particles would potentially threaten only those organisms that feed on soil, such as earthworms. The Bt Cry proteins have been tested against a wide variety of terrestrial and aquatic invertebrates, including earthworms, collembola, daphnids, insect predators and parasites, spiders, and honeybees. In most cases, no adverse effects were observed, even when test populations were exposed to toxin concentrations over 500-1,000-fold greater than those they would be expected to encounter under field conditions ${ }^{6}$.

The studies determining rates of degradation of Cry proteins in soil were mostly carried out in soil microcosms. But Head et al. ${ }^{15}$ have also investigated the fate of Bt toxins in soil under field conditions. Their study measured the level of CrylAc protein in soils collected from inside and outside fields where Bt cotton had been grown and the crop subsequently incorporated into soil by post-harvest tillage for three to six consecutive years. The amount of protein was evaluated using enzyme-linked immunosorbent assay and insect bioassays. Data showed that the amount of CrylAc protein in the soil was below the level of detection for both test methods and did not result in detectable biological activity.

\section{Persistence or invasiveness of crops}

It is also important to determine whether newly introduced traits make a crop more likely to be more persistent (weedy) in agricultural habitats or more invasive in natural habitats. The definition of weeds, invasive plants, and colonizers, together with their ecological characteristics, have been discussed by Williamson ${ }^{16}$. The characteristics that define plants of these kinds remain obscure. Luby and $\mathrm{M} \mathrm{CN}$ ichol ${ }^{17}$ and Baker ${ }^{18}$ stated that weediness arises from many different characters and that the addition of one gene is unlikely to cause a crop to become a weed. Both Fitter et al. ${ }^{19}$ and Williamson et al. ${ }^{20}$ oppose this statement and suggest that small genetic changes can cause large ecological alterations. Despitethe debate, there is consensus that if a crop species has very few weedy characteristics, the addition of one or a few genes would be unlikely to cause the crop to become a weed problem. Special attention must be given to crops that already have weedy characteristics or in which added genes might be expected to improve crop competitiveness in agricultural or natural habitats21.

$M$ any plant species can be found both as a crop and as a weed ${ }^{22}$. A change in habitat may potentially result in the evolution of a weed from a cultivated plant or from a feral plant that is closely related to a cultivated species ${ }^{19}$. Various authors s $^{3,21,23,24}$ have observed examples of this in and around cultivated land.

As a high proportion of current GM crops carry tolerance to a particular herbicide, these crops have been the most extensively studied. The current scientific evidence indicates that, in the absence of herbicide applications, GM herbicide-tolerant crops are no more likely to be invasive in agricultural fields or in natural habitats than their non-GM counterparts $21,25-29$.

The GM crops produced to date show little evidence of enhanced persistence or invasiveness. But the kinds of GM crops used in agri- culture so far, in biological terms, have been limited. Some of the biological changes possible, such as changes in tolerance to extremes of temperature, water, soil salinity regimes, the introduction of pest or pathogen resistance, and changes in seed dormancy and propagation characteristics, could potentially have significant effects on persistence and invasiveness. It is important, therefore, that we continue with a rigorous case-by-case assessment of GM crops, accompanied by relevant underpinning research.

\section{Gene flow from crops to related species}

GM crop plants may be able to hybridize with sexually compatible species and have an impact on the environment through the production of hybrids and their progeny. There are four basic elements in determining the likelihood and consequences of gene flow in this way: first, the distance of pollen movement from the GM crop; second, the synchrony of flowering between the crop and pollen recipient species; third, the sexual compatibility between crop and recipient species; and fourth, the ecology of the recipient species.

There is now extensive literature on the distance of pollen movement in different $\mathrm{crops}^{30}$. Some projects are engaged in mathematical modeling of pollen movement, and the general conclusion from the work to date is that pollination declines sharply with distance from the pollen source, but the distance at which pollination is zero is very difficult to determine. The distance viable pollen can travel is influenced by the pollen dispersal mechanism (wind, insects, etc.) and by pollen longevity, both of which are determined by plant species. Pollination distances of many kilometers have been recorded in some species ${ }^{31}$.

The sexual compatibility of crops with weeds and feral species has been reviewed by Ellstrand et al. ${ }^{32}$. He gives various examples of crops that can hybridize with weeds in some countries, including oilseed rape, barley, wheat, and beans. In the United Kingdom, the probability of hybridization with weeds is considered minimal for wheat, low for oilseed rape and barley, and high for sugar beet ${ }^{33}$.

The possibilities of hybridization between oilseed rape and related species have been reviewed by Scheffler et al.34,35. Several detailed studies of hybridization between oilseed rape and particular weed species have also been undertaken. Oilseed rape can hybridize with hoary mustard, with wild radish ${ }^{33}$, and with other wild brassicas species $3,34,35$.

The consequences of the transfer of novel genesfrom GM crops to weeds depend on the nature of the novel gene and the biology and ecology of the recipient weed species. The transfer of herbicidetolerance is unlikely to confer any competitive advantage to hybrids outsideagricultural areas. The transfer to weed species of characteristics such as resistance to particular pests and diseases or tolerance to stressful conditions (such as drought or salt tolerance) could potentially give weed species a selective advantage. In this context, Ramachandran et al. ${ }^{36}$ have investigated the competitive ability of an insect-resistant transgenic oilseed rape variety as compared with non-transgenic oilseed rape in seed mixtures. The transgenic variety was competitively superior when the two varieties were subject to diamondback moth selection pressure in greenhouse experiments and in field plots. In a similar study, Stewart et al. ${ }^{37}$ have shown, under certain conditions, the likelihood of increased fitness in oilseed rape varieties expressing Bt transgenes.

Some of the modifications made by GM plant breeding are likely to have direct parallels in conventional plant breeding. Therefore, experience of the impact of hybridization between conventional crop varieties and weed species in conventional agriculture may be highly instructive in regard to the interpretation of the impact of hybridization between GM crops and weed species. H owever, some possible future genetic modifications in GM plant breeding, such as salt tolerance or cold tolerance, could potentially produce novel crop 


\section{Fate of free DNA in the environment}

A novel DNA sequence encoding a trait could, in theory at least, enter the wider environment by several means. For example, plant DNA is present in soil or compost as a result of decaying plant residues. If a crop were GM, then the soil residue could also contain DNA encoding the novel trait. Similarly, the application of manure from animals eating a diet containing fodder from a GM plant could provide a route for the transfer of novel genes. Possible wider environmental impacts could also include the release of novel DNA in animal-derived products, for example, meat and milk used in the preparation of animal feed from GM crops.

To gain perspective when assessing the potential environmental impact of DNA from GM crops, it is important to consider the amount of DNA in the environment from non-GM origins. Pollen, leaves, and fruit alone result in thousands of tons of DNA per year being released into the environment ${ }^{62}$, in addition to the contribution from decaying plant and animal matter and release from microbes. It is important to emphasize that many of the genes being incorporated into GM crops are also present naturally in the environment ${ }^{63}$. The amount of DNA derived from GM crops as a proportion of the total is therefore likely to be small, even if such crops are grown on a commercial scale.

The longevity of DNA in soil depends on various factors, including soil type and the presence of soil nucleases that degrade DNA. Laboratory microcosm experiments show the degradation of all but $0.1 \%$ of the target DNA sequence from transgenic tobacco within 40 days ${ }^{64}$. A separate study involving the addition of free plasmid DNA to a microcosm showed the degradation of the polymer to below the limit of detection within five days. In addition to questions about the relevance of microcosm studies to the field situation, such studies also do not demonstrate the transforming capacity of the DNA for competent bacteria, on which its possible environmental impact depends.

The persistence of DNA in soil in the field seems to vary. Trace amounts of DNA from a transgenic tobacco trial were detected for several months in the field 65 , whereas less than $0.4 \%$ of the target sequence of a different trial remained after two weeks ${ }^{63}$, and small amounts of DNA remained on a site of transgenic sugar beet after two years. None of these studies, however, detected incorporation of a foreign gene into indigenous soil bacteria.

Few studies have investigated the persistence of DNA in compost, although bacteria carrying plasmids have been detected ${ }^{66}$ and gene transfer has been observed ${ }^{67}$. Similarly, there is a paucity of data on the survival of DNA in manure, although intact plasmids surviving in pig manure have been reported ${ }^{68-70}$, making DNA transfer following uptake at least theoretically possible.

The possible presence of genes in manure depends largely on the survival of DNA as it passes through the digestive tract of an animal

types whose impact on the environment will need to be assessed with particular care.

It is generally assumed that there is likely to be an environmental impact only if the novel trait acquired confers greater environmental fitness on the crop plant or its sexually compatible relative. This is not necessarily the case. A gene that confers reduced fitness on a plant in a wild habitat could adversely affect wild sexually compatible natural populations through recurrent pollination by a GM crop $^{38}$.

Another matter of importance is the potential of crops carrying different herbicide-tolerance genes to become multiply tolerant to several herbicides by pollination between adjacent crops. In several closely studied examples in Canada, farmers have detected oilseed rape plants tolerant to three different herbicides ${ }^{39}$. Two of the toler- fed a diet containing GM material. Limited studies to date have found no evidence of plant-derived DNA in manure from chickens or cattle fed grain or silage from $B t$ maize ${ }^{71}$. This may be due to degradation of the gene by nucleases in the animal gut ${ }^{72,73}$.

Transfer of genes via animal feed derived from GM crops must also be considered in terms of possible wider environmental impact. On the basis of evidence to date, survival through the entire gastrointestinal tract seems unlikely. For example, transgenic DNA from glyphosate tolerant soybeans incubated in simulated gastric fluid was completely degraded within 15 seconds ${ }^{74}$

Even if "free" DNA does persist in the gut long enough to be taken up by bacteria, the possibility of gene transfer with other gut microbes should be considered. We know of no in vivo studies of this in ruminants, but gene transfer has been observed between cultured rumen bacteria in the laboratory ${ }^{75-77}$. It is, however, difficult to extrapolate these studies to what happens in vivo, but the nuclease activity in the rumen ${ }^{78}$ will cause DNA degradation, making the survival of intact genes in the rumen unlikely.

There is no evidence suggesting that functional genes are incorporated into meat products from animals fed GM feed. This is worthy of consideration, as decaying carcasses, for example, could be a possible source of the transfer of novel genes into the environment. Although plant-derived, non-transgenic DNA was detected in the meat from chickens on a diet of whole, unprocessed $B t$ maize, the $B t$ transgene was not found in the meat. Eggs and milk are another possible route for of gene transfer, but the evidence to date shows no transgenic material in either of these products resulting from animals fed on GM material65.

We have also considered the possibility of gene transfer in the preparation of animal feed. Aside from the obvious issues of segregation at the point of harvest and processing, DNA survival during feed preparation is also an important issue. It seems that only feed that has undergone heat processing, chemical expulsion, or extrusion contains DNA degraded to the point that it can no longer act as a source of functional genes ${ }^{79,80}$.

Silage is an important animal feed, and will also contain intact plant genes ${ }^{79}$. Fragments of transgenic DNA persisted in silage made from $B t$ maize for up to 106 days while shorter, nonfunctional fragments survived for up to 7 months after ensilage ${ }^{81}$. The possibility of effluent from silage fermentation containing functional genes is low; plasmid DNA was undetectable after exposure to silage effluent for just 30 seconds. Further studies on the survival of non-GM maize chromosomal DNA in silage effluent showed degradation of the DNA after one minute ${ }^{82}$.

ances were acquired from GM crops and the third from conventional breeding. Various studies are ongoing in Europe to definemanagement practices that will minimize the likelihood of this occurring. Unless agronomics and weed control measures are managed well, the development of multiple tolerance in "volunteer" crop plants (from seeds remaining viablein agricultural soil) may also impact the environment by necessitating the use by farmers of less environmentally friendly (and possibly outdated) herbicides.

\section{Reduced efficiency of pest, disease, and weed control}

Changes in agronomic practice associated with the introduction of particular GM crops could also have potential impacts on the environment. These include the increased use of broad-spectrum herbicides, the more frequent sowing of a crop (e.g., winter sowing 
instead of spring), or the increased use of minimal cultivation agriculture. Some of the indirect effects may be beneficial to the environment; for example, minimal cultivation generally reduces soil erosion and favors earthworms; here, however, we focus on potential negative effects on the environment.

Weeds resistant to herbicides can develop by evolution and selection from within weed populations continually sprayed with the same herbicide (rather than by gene flow from a herbicide tolerant crop). Weed species have historically displayed a remarkable ability to evolve tolerance to particular herbicides. Several studies have demonstrated that tolerance to a particular herbicide is often more likely to develop by evolution from within the weed gene pool rather than by gene flow from herbicide-tolerant crops $^{40,41}$. Glyphosate tolerance was considered to be highly unlikely to evolve in weed species in this way. However, there is now a well-characterized example in annual ryegrass in Australia ${ }^{42}$ and a recently published example in horseweed in the United States ${ }^{43}$.

Farmers and plant breeders have for many years struggled to keep ahead of a pest's ability to adapt to the techniques used to control it. Experience with chemical pesticides has proved challenging, as pests evolve resistance to chemical pesticides ${ }^{44,45}$. Pests have al so historically overcome resistance introduced into crop plants by traditional breeding programs ${ }^{46}$. More recently, several studies have shown that pests can also adapt to Bt toxins produced by biopesticide sprays containing $B$. thuringiensis under field and laboratory conditions $^{47}$. Pest resistance to GM Bt crops has been observed under laboratory condition $s^{48}$ but not, to our knowledge, under field conditions to date.

It is possible that the widespread use of Bt crops could lead to the evolution of several important insect pests that are resistant to the Bt biopesticide. This could potentially make it necessary to resort to less environmentally acceptable chemical pesticides. This is of particular concern to organic farmers because they use the Bt bacterium as a permitted pesticide. Several strategies for resistance management have been proposed to delay adaptation to Bt crops by pest populations $s^{44}$. The most widely used is the "high-dose refuge" strategy, which has been implemented in North America ${ }^{49}$. The implementation of effective resistance-management practices is crucial to obtain the greatest benefits from pest-resistant transgenic crops and to allow the continued effective use of $\mathrm{Bt}$ biopesticides. An important part of good resistance management is to sow a refuge area of the crop, an area of the total crop that is deliberately susceptible to the pest. Where resistance to Bt in insects is controlled by recessive genes, the presence of refuge plants reduces the probability of the evolution of insects with resistance to the Bt toxin.

The next generation of GM pest-resistant varieties is likely to contain additional insecticidal genes. This pyramiding strategy is expected to delay the evolution of resistance much more effectively than the presence of a single insecticidal toxin and may require smaller refuges ${ }^{50}$. The cotton variety sGK containing two insecticidal genes, crylA and CPT 1 (cowpea trypsin inhibitor), is being planted commercially in China. Other stacked CrylAc and Cry2AB Bt varieties are also being developed. Cross-resistance among the toxins is a potential risk to the use of pyramids, and Roush ${ }^{50}$ suggests that $100 \%$ mortality of susceptible insects on the GM crop is more critical to delaying the onset of resistance.

It is important to emphasize that a recent survey conducted by US maize growers ${ }^{51}$ has shown that, in the year 2000 , almost $30 \%$ of the farmers failed to comply with the refuge protocols designed to prevent or delay the emergence of insects resistant to Bt toxins. This rate of non-compliance could well increase the risk of plant resistance breakdown. There is to date no reported evidence of insect resistance to Bt crops under field conditions in the United States, although Bt- resistant insects have been observed in areas where Bt biopesticides are sprayed on crops $^{49}$.

\section{Effects on wildlife biodiversity}

The widespread introduction of GM herbicide-tolerant crops may cause a shift in weed populations and thus reduce weed species diversity and ecosystem complexity in the GM field and on neighboring farms. Herbicides are widely used in conventional agriculture and few weeds are normally observed in many non-GM crops following standard herbicide treatments. It is argued, however, that because the currently available GM herbicide-tolerant crops confer tolerance to broad-spectrum herbicides such as glufosinate and glyphosate, their extensive use may reduce the diversity of weeds in agricultural habitats.

It is debatable how broadly applicable these herbicides will be in practice and it is unclear what their precise impact will be on weed populations in comparison with the range of herbicides (some relatively persistent) currently used in conventional agriculture. The Farm Scale Evaluations currently being carried out in the United Kingdom and due to report in 2003 are designed specifically to compare the impact on wildlife biodiversity of GM herbicide-tolerant crops with conventional crops of the sametype ${ }^{52}$.

The preciseimpact of theintroduction of herbicide-tolerant crops will depend on the rotational and agronomic practices adopted to manage them. The adoption of different herbicide-use programs may have different effects on plant and animal biodiversity in fields and field margins ${ }^{53-55}$. Radosevich et al. ${ }^{56}$ predicted that shifts in weed species composition and abundance would be exacerbated with the consecutive use of the same herbicide, providing favorable conditions for growth of particular weeds, insects, and diseases. Weeds exhibit considerable plasticity and thus are able to adapt to a wide range of cultivation practices. Experience with conventional agriculture has shown that weed species composition will vary within the same crop, among different fields, and at different times of year ${ }^{52}$. Thus, weed population shifts are natural ecological phenomenain crop management and should not be viewed as exclusive to GM crops. The effect of changes in herbicide programs on plant and animal biodiversity in field and field margins are being investigated in the United Kingdom ${ }^{27}$.

\section{Effects on soil and water}

It is sometimes argued that the use of herbicides will increase with the widespread introduction of GM herbicide tolerant crops and that this will contribute to the contamination of soil and groundwater and have undesirable effects on plant and animal diversity. However, no significant change in the overall amount of herbicide use has been observed with the adoption of herbicide-tolerant crops in the United States ${ }^{57}$. A small but significant decrease in herbicide use has been reported in the United States since the introduction of GM soybeans $s^{58,59}$. An analysis by US soybean growers reported by Trewavas and Leaver ${ }^{60}$ shows that 7.2 million pounds of other herbicides have been replaced by 5.4 million pounds of glyphosate. This substitution resulted in the replacement of herbicides that are at least three times more toxic and that persist nearly twice as long as glyphosate ${ }^{57}$. Furthermore, the Canola Council of Canada ${ }^{61}$ reported the results of a study that shows that herbicidetolerant oilseed rape eliminated the use of $>6000$ tones of herbicide in the 2000 growing season.

Another important benefit of the use of herbicide-tolerant GM crops in the US is that they facilitate zero-till agronomic systems, which contributes to a reduction in soil erosion. There are, however, still active discussions on the significance of these kinds of data and on the long-term impact of the use of broad-spectrum herbicides ${ }^{52}$. 


\section{Future perspectives}

In considering the impact of agriculture on the environment, the variables are numerous. However, there is extensive experience to draw upon in past studies of theenvironmental impact of conventional agricultural crops. It is important to examine the different potential impacts of GM crops within the context of this wider knowledge. As a consequence of the discussions about the commercialization of GM crops in some parts of the world, questions are being asked that were rarely considered for conventionally bred crops. This is true even though the products of many methods of conventional plant breeding (e.g., induced mutation and hybridization with wild relatives) carry a high level of unpredictability. The questions currently being asked of GM crops frequently demand a degree of forensic precision that would be impossible to apply to the products of moretraditional breeding.

To minimize potential adverse effects of pest and disease resistance in GM plants on benign and beneficial organisms, it is important to target an appropriate level of gene expression to the parts of the plant where the resistance mechanism is needed. Targeting pest or disease control to the primary pest or disease is a demanding prospect, whether using chemical or biological approaches. To improve targeting of gene expression, the range of tissue-specific gene promoters needs to be diversified. It is also important that assessments of the impact of resistance mechanisms are collected from ecologically relevant in vivo agricultural environments. Laboratory experiments are important in establishing the principles that might influence nontarget effects on friendly organisms, but care needs to be exercised in extrapolating their significance to the wider environment. Field experiments for this purpose are not trivial and often require several years of data in different locations to gather meaningful data.

It is rarely possible to make generic judgments about the persistence or invasiveness in the environment of GM crops or their progeny. The novel genes inserted into GM crops to date have been restricted in their likely biological impact. In the regulatory process, all classes of GM crop, especially novel genetic changes, must be assessed on a case-by-case basis in the context of the geographical locations where they are to be grown. The plant characteristics that need particular attention are those that significantly improve tolerance to biotic and abiotic stresses. Changes in breeding system and seed characteristics also have the potential significantly to alter survival and invasiveness. M ost studies to date on gene flow have concentrated on the likelihood of a novel gene being transferred to a related wild or weedy plant species. However, further studies are needed on the ecology of potential gene recipient populations to assess the consequences of the transfer of a particular transgenic plant character, such as resistance to disease or pests, or an increase in cold tolerance.

$M$ anagement of resistance mechanisms for pests and diseases is often difficult, regardless of the mechanism of control used. The spread of corn blight (Helminthosporium maydis) across the United States in 1970 is a dramatic example of what can happen if the genetic basis of resistance is allowed to become too narrow. The experience with Bt crops has demonstrated the importance of the management of resistance in Bt maize crops. One of the significant features of GM technology is that it can make possiblethe use of similar pestor disease-resistance mechanisms in a diverse range of crops. This could potentially lead to intense selection pressures on pests and diseases to overcome resistance.

The diversity of resistance mechanisms used commercially in GM crops has, to date, been limited; it would benefit from using a wider range of different approaches operating in the same crop (transgene pyramiding) and in different crops. The same principle of resistance management also applies to herbicidetolerant crops. In this case, the use of different herbicide-tolerance genes in different varieties of the same crop species (e.g., oilseed rape) can lead by geneflow to volunteer crop plants and weeds becoming tolerant to several herbicides. This could make it necessary to resort to the use of herbicides that are environmentally less acceptable. In the future, it will likely be even more important to identify ways of encouraging or enforcing good management of pest, disease, and weed control strategies in agriculture.

Another issue related to gene flow is whether novel DNA sequences in GM plants (in themselves) impact the environment in ways different from the tons of DNA passing into the environment from other sources. While many of the DNA sequences introduced into GM plants are already present in nature, the combinations and quantities of particular DNA sequences may change under exploitation of GM crops. However, the proportion of the DNA with novel combinations of sequences will always bea minute proportion of the whole (e.g., one novel gene construct introduced into a wheat plant with about 80,000 resident genes). To ascertain the significance of the presence of novel DNA combinations in the wider environment, it would be important to establish the approximate background levels of particular genes at present. There have been few studies directly comparing survival of identical genes encoded in organisms of GM and non-GM origins. Conclusions are therefore derived by extrapolation from field and microcosm studies that may not necessarily have been conducted identically. A systematic analysis of these issues would therefore be helpful.

In considering the fate and possible impact of novel DNA sequences in the environment through manure, compost, animal feed, and crop remains deposited in soils, the critical issue is whether the DNA survives long enough to be transferred to other organisms. If this happens in nature, the most likely route is through competent bacteria. However, our knowledge of the incidence of bacterial competence under field conditions is limited. Furthermore, techniques used to detect DNA give little indication of the functional capabilities of the DNA to act as a source of transforming DNA. If a DNA fragment does not retain functional integrity, it is unlikely to have any environmental impact.

We mentioned at the outset the question of how to determine the significance of an environmental impact. It can be difficult to obtain objective data on environmental impact that is a true reflection of what happens in an agricultural habitat. Even more difficult is the decision of whether a particular impact is acceptable or unacceptable. The problem is illustrated by the question: if a particular GM crop is found to reduce earthworm numbers (e.g., by $50 \%$ ) and this is considered an unacceptable environmental impact, would it follow that conventional agricultural practices with a similar impact on earthworms should be restricted?

Discussions about baselines for comparison of GM crops have in some countries grown out of concerns that some conventional agricultural practices have had a significant negative impact on the environment. In the United Kingdom, for example, where over $70 \%$ of the land area is farmed in some way, there is clear evidence of a significant reduction of certain species of farmland birds over the past 30 years. The case-by-case analysis of the environmental impact of GM crops as part of regulatory assessment has considerable merit, but it can lack vision about indirect effects on the environment that may be associated with the introduction of particular crops.

There is the possibility that if GM crops provide a new dimension of control over pests, diseases, and weeds in a poorly targeted way, they will drive agriculture farther toward monoculture and the excessive control of the agricultural environment. In this scenario, control would be exploited primarily to maximize crop productivity at the expense of supporting a diversity of wildlife food chains (such as those of insects, seeds, weeds, or birds) and habitats in the environment. These impacts on the environment as we have discussed are not restricted to GM crops, but one of the biggest challenges for the future is to manage the introduction and widespread commer- 
cialization of GM crops in a way that favors the environment. It will be necessary to provide incentives that will require GM crops to be combined with agronomic practices that nurture crop diversity, sound crop rotation, soil fertility, and wildlife biodiversity, and that minimize the impact of agriculture on the environment.

\section{Acknowledgments}

Wethank the Biotechnology and Biological Sciences Research Council for their support. The majority of the literature discussed in this review was collected and presented as part of a project supported by the D epartment for Environment, Food and Rural Affairs (DEFRA; Contract Number OF0193) in a project entitled: "Review of knowledge of the potential impacts of GM O s on organic agriculture." We are greatly indebted to DEFRA for their support and to Bruce Pearce, James Welsh, and M artin Wolfe of the Initiative on O rganic Research, Elm Farm Research Centre, United Kingdom, for their valuable collaboration and discussions. Wethank Ruth Peart for help with the literature search and Helen Ghirardello for preparation of the manuscript.

\section{Received M ay 2002; accepted 13 M ay 2002}

1. Kessler, C. \& Economides, I. (eds). EC-Sponsored Research on Safety of Genetically Modified Organisms. http://europa.eu.int/comm/research/quality-oflife/gmo/.

2. James, C.A. Global Review of Commercialized Transgenic Crops, 2001, ISAAA Briefs No. 24 (ISAAA, Ithaca, NY, 2001).

3. National Research Council. Genetically Modified Pest Protected Plants: Science and Regulation (National Research Council, National Academy Press, Washington, DC, 2000)

4. Losey, J.E., Rayor, L.S. \& Carter, M.E. Transgenic pollen harms monarch larvae. Nature 399, 214 (1999).

5. Sears, M.K. et al. Impact of Bt corn pollen on monarch butterfly populations: A risk assessment. Proc. Natl. Acad. Sci. USA 98, 11937-11942(2001).

6. Zangerl, A.R. et al. Effects of exposure to event 176 Bacillus thuringiensis corn pollen on monarch and black swallowtail caterpillars under field conditions. Proc. Natl. Acad. Sci. USA 98, 11908-11912 (2001).

7. Hilbeck, A., Moar, W.J., Pusztai-Carey, M., Filippini, A. \& Bigler, F. Toxicity of Bacillus thuringiensis Cry1 $\mathrm{Ab}$ toxin to the predator Chrysoperla carnea (Neuroptera: Chrysopidae). Environ. Entomol. 27, 1255-1263 (1998).

8. Hilbeck, A. et al. Effects of transgenic Bacillus thuringiensis corn-fed prey on mortality and development time of immature Chrysoperla carnea (Neuroptera: Chrysopidae). Environ. Entomol. (1998).

9. US Environmental Protection Agency. Sets of scientific issues being considered by the Environmental Protection Agency regarding Bt plant-pesticides risk and benefit assessments (SAP Report no. 2000-07, FIFRA Scientific Advisory Panel Meeting, October 18-20, 2000) (EPA, Washington, DC, 2000). http://www.epa.gov/scipoly/sap/2000/october/octoberfinal.pdf.

10. Hoy, C.W. et al. Naturally occurring biological controls in genetically engineered crops. in Conservation Biological Control (ed. Barbosa, P.) 185-205 (Academic Press, London, 1998).

11. Pimental, D.S. \& Raven, P. Bt corn pollen impacts on nontarget Lepidoptera: assessment of effects in nature. Proc. Natl. Acad. Sci. USA. 97, 8198-8199 (2000).

12. Carrièrre, Y. et al. Large-scale management of insect resistance to transgenic cotton in Arizona: Can transgenic insecticidal crops be sustained? J. Econ. Entomol. 94, 315-325 (2001).

13. Saxena, D. \& Stotzky, G. Insecticidal toxin from Bacillus thuringiensis is released from roots of transgenic BT corn in vitro and in situ. FEMS Microbial Ecol. 33, 35-39 (2000).

14. Stotzky, G. Persistence and biological activity in soil of insecticidal proteins from Bacillus thuringiensis and of bacterial DNA bound on clays and humic acids. J. Environ. Qual. 29, 691-705 (2000).

15. Head, G., Surber, J. B., Watson, J.A., Martin, J.W. \& Duan, J.J. No detection of Cry1Ac protein in soil after multiple years of transgenic Bt cotton (Bollgard) use. Environ. Entomol. 31, 30-36 (2002).

16. Williamson, M. Invaders, weeds and the risk from genetically manipulated organisms. Experimentia 49, 219-224 (1993).

17. Luby, J.J. \& McNichol, R.F. Gene flow from cultivated to wild raspberries in Scotland: developing a basis for risk assessment for testing and deployment of transgenic cultivars. Theor. Appl. Genet. 90, 1133-1137 (1995).

18. Baker H.G. The evolution of weeds. Annu. Rev. Ecol. Systematics 5, 1-24 (1974).

19. Fitter A., Perrins J. \& Williamson M. Weed probability challenged. Biotechnology (NY) 8, 473 (1990).

20. Williamson, M., Perrings, J. \& Fitter, A. Releasing genetically engineered plants: present proposals and possible hazards. Trends Ecol. Evol. 5, 417-419 (1990).

21. Ammann, K., Jacot, Y. \& Al Mazyad, R. Weediness in the light of new transgenic crops and their potential hybrids. Zeitschrift Pflanzenkrankheiten Pflanzenschutz J. Plant Dis. 17, 19-29 (2000).

22. Keeler, K.H., Turner, C.E. \& Bolick, M.R. Movement of crop transgenes into wild plants. in Herbicide-Resistant Crops-Agricultural, Environmental, Economic, Regulatory, and Technical Aspects (ed. Duke, S.O.) 303-330 (Lewis Publishers, London, 1996).

23. Boudry, P., Morchen, M., Saumitou-Laprade, P., Vernet, P. \& Van Dijk, H. The origin and evolution of weed beets: consequences for the breeding and release of herbicide-resistant transgenic sugar beets. Theor. Appl. Genet. 87, 471-478 (1993).

24. National Research Council. Field Testing Genetically Modified Organisms: Framework for Decision. (National Academy Press, Washington DC, 1989).

25. Lavigne, C. et al. A pollen-dispersal experiment with transgenic oilseed rape. Estimation of the average pollen dispersal of an individual plant within a field. Theor. Appl. Genet. 96, 886-896 (1998).

26. Hails, R.S., Reeds, M., Kohn, D.D. \& Crawley, M.J. Burial and seed survival in Brassica napus subsp. Oleifera and Sinapis arvensis including a comparison of transgenic and non-transgenic lines of the crop. Proc. R. Soc. Lond. B Biol. Sci. 264, 1-7 (1997).

27. Sweet, J.B. \& Shepperson, R. The impact of releases of genetically modified her- bicide tolerant oilseed rape in UK. Acta Horticult. 459, 225-234 (1997)

28. Snow, A.A., Andersen, B. \& Jorgensen, R.B. Costs of transgenic herbicide resistance introgressed from Brassica napus into weedy B. rapa. Mol. Ecol. 8, 605-615 (1999).

29. Crawley, M.J., Brown, S.L., Hails, R.S., Kohn, D.D. \& Rees, M. Transgenic crops in natural habitats. Nature 409, 682-683 (2001).

30. Lutman, P. (ed.). Gene Flow and Agriculture: Relevance for Transgenic Crops (BCPC Symposium Proceedings no. 72, Keele Proceedings) (British Crop Protection Council, London, 1999).

31. Squire, G.R., Crawford, J.W., Ramsay, G., Thompson, C. \& Bown, J. Gene flow at the landscape level. in Gene Flow and Agriculture: Relevance for Transgenic Crops (ed. Lutman, P.W.) 57-64 (British Crop Protection Council, London, 1999).

32. Ellstrand, N.C., Prentice, H.C. \& Hancock, J. Gene flow and introgression from domesticated plants into their wild relatives. Annu. Rev. Ecol. System 30, 539-563 (1999).

33. Raybould, A.F. \& Gray, A.J. Genetically modified crops and hybridisation with wild relatives: a UK perspective. J. Appl. Ecol. 30, 199-219 (1993).

34. Sheffler, J.A. \& Dale, P.J. Opportunities for gene transfer from transgenic oilseed rape (Brassica napus) to related species. Trans. Res. 3, 263-278 (1994).

35. Scheffler, J.A., Parkinson, A. \& Dale, P.J. Evaluating the effectiveness of isolation distances for field plots of oilseed rape (Brassica napus) using a herbicide-resistance transgene as a selectable marker. Plant Breed. 14, 317-321 (1995).

36. Ramachandran, S., Buntin, D., All, J.N., Raymer, P.L. \& Stewart, C.N. Intraspecific competition of an insect-resistant transgenic canola in seed mixtures. Agron. J. 92, 368-374 (2000).

37. Stewart, C.N., All, J.N., Raymer, P.L. \& Ramachandran, S. Increased fitness of transgenic insecticidal rapeseed under insect selection pressure. Mol. Ecol. 6, 773-779 (1997).

38. Giddings, G. Modelling the spread of pollen from Lolium perenne. The implications for the release of wind-pollinated transgenics. Theor. Appl. Genet. 100, 971-974 (2000).

39. Orson, J. Gene stacking in herbicide tolerant oilseed rape: lessons from the North American experience (English Nature Reports no. 443) (English Nature, London, 2002).

40. Moyes, C.L. et al. Barriers to gene flow from oilseed rape (Brassica napus) into populations of Sinapis arvensis. Mol. Ecol.11, 103-112 (2002)

41. Senior, I.J. \& Dale, P.J. Herbicide tolerant crops in agriculture: oilseed rape as a case study. Plant Breed., 121, 97-101 (2002)

42. Pratley, J., Baines, P., Eberbach, P., Incenrti, M. \& Broster, J. Glyphosate Resistance in Annual Ryegrass. Proceedings of the $11^{\text {th }}$ Conference of the Grassland Society of New South Wales, Australia. (The Grassland Society of NSW, Wagga, Wagga, 1996).

43. VanGessel, M.J. Glyphosate-resistant horseweed from Delaware. Weed Sci. 49, 703-705 (2001).

44. Raymond, M, Callaghan, A., Fort, P. \& Pasteur, N. Worldwide migration of amplified insecticide resistance genes in mosquitoes. Nature 350, 151-153 (1991).

45. Gould, F., Kennedy, G.G. \& Johnson, M.T. Effects of natural enemies on the rate of herbivore adaptation to resistant host plants. Entomol. Experiment. Applicata 58, 1-14 (1991).

46. Gould, F. Sustainability of transgenic insecticidal cultivars: integrating pest genetics and ecology. Annu. Rev. Entomol. 43, 701-726 (1998).

47. Gould, F. Testing Bt refuge strategies in the field. Nat. Biotechnol. 18, 266-267 (2000).

48. Shelton, A.M., Zhao, J.-Z \& Roush, R.T. Economic, ecological, food safety, and social consequences of the deployment of Bt transgenic plants. Annu. Rev. Entomol. 47, 845-881 (2002).

49. Alstad, D.N. \& Andow, D.A. Managing the evolution of insect resistance to transgenic plants. Science 268, 1894-1896 (1995).

50. Roush, R.T. Two-toxin strategies for management of insecticidal transgenic crops: can pyramiding succeed where pesticide mixtures have not? Philos. Trans. $R$. Soc. Lond. B Biol. Sci. 353, 1777-1786 (1998).

51. Dove, A. Survey raises concerns about Bt resistance management. Nat. Biotechnol. 19, 293-294 (2001)

52. UK Agriculture and Environment Biotechnology Commission. Crops on Trial (AEBC Report no. 21, September 2001, DTI Pub. 5650/2k/08/01/NP, URN 01/1083) (UK Agriculture and Environment Biotechnology Commission, London, 2001).

53. Burnside, O.C. An agriculturalist's viewpoint of risks and benefits of herbicideresistant cultivars. in Herbicide-Resistant Crops-Agricultural, Environmental, Economic, Regulatory, and Technical Aspects (ed. Duke, S.O) 391-406 (Lewis Publishers, London, 1996).

54. Giaquinta, R.T. An industry perspective on herbicide tolerant crops. Weed Technol. 6, 640 (1992).

55. Altieri, M.A. The ecological impacts of transgenic crops on agroecosystem health. 
Ecosystem Health 6, 13-23 (2000).

56. Radosevich, S.R., Ghersa, C.M. \& Comstock, G. Concerns a weed scientist might have about herbicide-tolerant crops. Weed Technol. 6, 635 (1992).

57. Heimlich, R.E. et al. Adoption of genetically engineered seed in US agriculture: implication for pesticide use (USDA Publication sld001) (USDA, Washington, DC, 2000). http://www.ers.usda.gov/Emphases/Harmony/fft/sld001.htm.

58. United States Department of Agriculture. Genetically engineered crops: has adoption reduced pesticide use? Agricultural Outlook August (2000). www.ers.usda.gov/publications/agoutlook/aug2000/ao273f.pdf

59. Anonymous. GM crops reduce pesticide use. AgBiotech Bulletin 9, Issue 6, August (2001). http://www.agwest.sk.ca/bulletin/abb_aug01.pdf

60. Trewavas, A. \& Leaver, C. Is opposition to GM crops science or politics? An investigation into the arguments that GM crops pose a particular threat to the environment. EMBO Reports 2, 455 (2001) http://www.emboreports.oupjournals.org/cgi/content/full/2/6/455

61. Canola Council of Canada. An Agronomic and Economic Assessment of Transgenic Canola (Canola Council of Canada, 2001). http://www.canolacouncil.org/production/gmo toc.html

62. Doerfler, W. \& Schubbert, R. Uptake of foreign DNA from the environment: the gastrointestinal tract and the placenta as portals of entry. Weiner Klinische Wochenschrif 110-2, 40-44 (1998).

63. Department for Environment, Food and Rural Affairs. Review of knowledge of the potential impacts of GMOs on organic agriculture. in press (2002).

64. Widmer, F., Seidler, R.J. \& Watrud, L.S. Sensitive detection of transgenic plant marker gene persistence in soil microcosms. Mol. Ecol. 5, 603-613 (1996).

65. Paget, E., Lebrun, M., Freyssinet, G. \& Simonet, P. The fate of recombinant plant DNA in soil. Euro. J. Soil Biol. 34, 81-88 (1998).

66. McDonald, I.R., Riley, P.W., Sharp, R.J. \& McCarthy, A.J. Survival of plasmid-containing Bacillus subtilis released into mushroom compost. Microb. Ecol. 36, 51-59 (1998).

67. Amner, W., McCarthy, A.J. \& Edwards, C. Quantitative assessment of factors affecting the recovery of indigenous and released thermophilic bacteria from compost. Appl. Environ. Microbiol. 54, 3107-3112 (1988).

68. Smalla, K. et al. Exogenous isolation of antibiotic resistance plasmids from piggery manure slurries reveals a high prevalence and diversity of IncQ-like plasmids. Appl. Environ. Microbiol. 66, 4854-4862 (2000).

69. Gotz, A. et al. Detection and characterisation of broad-host-range plasmids in environmental bacteria by PCR. Appl. Environ. Microbiol. 62, 2621-2628 (1996).
70. Gotz, A. \& Smalla, K. Manure enhances plasmid mobilisation and survival of Pseudomonas putida introduced into field soil. Appl. Environ. Microbiol. 63, 1980-1986 (1997)

71. Einspanier, R. et al. The fate of forage plant DNA in farm animals: a collaborative case study investigating cattle and chicken fed recombinant plant material. Euro. Food Res. Technol. 212, 129-134 (2001).

72. McAllan, A.B. The degradation of nucleic acids in, and removal of breakdown products from, the small intestine of steers. Brit. J. Nutrition 44, 99-113 (1980).

73. McAllan, A.B. The fate of nucleic acids in ruminants. Proc. Nutrition Soc. 41, 309-317 (1982).

74. Harrison, L.A. et al. The expressed protein in glyphosate-tolerant soybeans, 5enolpruvl-shikimate-3-phosphate synthase from Agrobacterium sp. is rapidly digested in vitro and is not toxic in acutely gavaged mice. J. Nutr. 126, 728-740 (1996).

75. Morrison, M. Do ruminal bacteria exchange genetic material? J. Dairy Sci. 79, 1476-1486 (1996)

76. Mercer, D.K., Melville, C.M., Scott, K.P. \& Flint, H.J. Natural genetic transformation in the rumen bacterium Streptococcus bovis JB1. FEMS Microbiol. Lett. 179, 485-490 (1999)

77. McConnell, M.A., Mercer, A.A. \& Tannock, G.W. Transfer of plasmid pAM1 between members of the normal microflora inhabiting the murine digestive tract and modification of the plasmid in a Lactobacillus reuteri host. Microb. Ecol. Health Dis. 4, 343-355 (1991).

78. Flint, H.J. \& Thomson, A.M. Deoxyribonuclease activity in rumen bacteria. Lett. Appl. Microbiol. 11, 18-21 (1990).

79. Chiter, A., Forbes, J.M. \& Blair, G.E. DNA stability in plant tissues: implications for the possible transfer of genes from genetically modified food. FEBS Lett. 481, 164-168 (2000).

80. Forbes, J.M. Blair, G.E., Chiter, A., \& Perks, A. Effect of Feed Processing Conditions on DNA Fragmentation. Section 5: Scientific Report 376. (UK Ministry of Agriculture, Fisheries \& Food, London; 1998).

81. Hupfer, C., Mayer, J., Hotzel, H., Sachse, K. \& Engel, K.-H. The effect of ensiling on PCR-based detection of genetically modified Bt maize. Europ. Food Res. Technol. 209, 301-304 (1999).

82. Duggan, P.S., Chambers, P.A., Heritage, J. \& Forbes, J.M. Survival of free DNA encoding antibiotic resistance from transgenic maize and the transformation activity of DNA in ovine saliva, ovine rumen fluid and silage effluent. FEMS Microbiol. Lett. 191, 71-77 (2000). 


\section{Research Errata}

\section{Excision of selectable marker genes from transgenic plants}

Peter D. Hare \& Nam-Hai Chua

Nat. Biotechnol. 20, 575-580 (2002)

In the June 2002 issue, the references in the footnote of Table 2 in the above review were printed incorrectly. The footnote should read:

"PShown to be functional in plastids ${ }^{23,51}$." We apologize for any confusion this may have caused.

\section{Potential for the environmental impact of transgenic crops}

Philip J. Dale, Belinda Clarke \& Eliana M.G. Fontes

Nat. Biotechnol. 20, 567-574 (2002)

In the June 2002 issue, the received date for the above review was printed incorrectly. The correct received date is 3 April 2002 , not May 2002.

We apologize for the error.

\section{Molecular strategies for gene containment in transgenic crops}

\section{Henry Daniell}

Nat. Biotechnol. 20, 581-586 (2002)

In the June 2002 issue, the above review stated on p. 583 that "One way of accomplishing this (gene containment) is with a system dubbed "terminator technology," which was patented several years ago by the United States Department of Agriculture (USDA; Germantown, MD), Cornell University (New York, NY) Purdue University (West Lafayette, IN and Iowa State university (Ames, IA), and licensed to Delta and Pine Land Company (D\&PL; Scott, MS), which was subsequently bought by Monsanto (St. Louis, MO).” In fact, the three patents on which the Technology Protection System is based, Control of Plant Gene Expression (U.S. patents 5,723,765, 5,925,808, and 5,977,441), are jointly owned by D\&PL and the USDA. This is because employees of D\&PL and the USDA were the inventors of this technology. Second, Cornell University, Purdue University, and Iowa State University were never involved in the development of this technology and hold no ownership in it. Third, D\&PL did not license the technology as it is a co-owner; instead, in July 2001, it signed with the USDA a licensing agreement that gave D\&PL the exclusive right, and the responsibility, to market the technology to third parties and pay royalties to the USDA. Fourth, D\&PL was not bought by Monsanto and remains an independent, publicly traded company (DLP on the NYSE). We apologize for the error. 